\title{
Radioresistant breast cancer cells exhibit increased resistance to chemotherapy and enhanced invasive properties due to cancer stem cells
}

\author{
YOUNG SHIN KO ${ }^{1}$, HANA JIN ${ }^{1}$, JONG SIL LEE ${ }^{2}$, SANG WON PARK $^{1}$, KI CHURL CHANG $^{1}$, \\ KI MUN KANG ${ }^{3}$, BAE KWON JEONG ${ }^{3}$ and HYE JUNG KIM ${ }^{1}$ \\ Departments of ${ }^{1}$ Pharmacology, ${ }^{2}$ Pathology and ${ }^{3}$ Radiation Oncology, School of Medicine, \\ Institute of Health Sciences, Gyeongsang National University, Jinju 52727, Republic of Korea
}

Received April 3, 2018; Accepted September 13, 2018

DOI: $10.3892 /$ or.2018.6714

\begin{abstract}
Previous studies suggest that cancer stem cells (CSCs) exist in solid tumors, and contribute to therapeutic resistance and disease recurrence. Therefore, the present study aimed to investigate whether radioresistant (RT-R) breast cancer cells derived from breast cancer cells increase the number of CSCs, and whether these CSCs are responsible to increased invasiveness and therapeutic resistance. MCF-7, T47D and MDA-MB-231 cells were irradiated 25 times (2 Gy each; $50 \mathrm{~Gy}$ total) to generate radioresistant breast cancer cells (RT-R-MCF-7, RT-R-T47D and RT-R-MDA-MB-231). RT-R-breast cancer cells demonstrated increased cell viability against irradiation and increased colony forming abilities compared with parental breast cancer cells. Particularly, RT-R-MDA-MB-231 cells derived from highly metastatic MDA-MB-231 cells exhibited most radioresistance and chemoresistance of the three cell lines. In addition,
\end{abstract}

Correspondence to: Professor Hye Jung Kim, Department of Pharmacology, School of Medicine, Institute of Health Sciences, Gyeongsang National University, 816 Beongil 15 Jinjudaero, Jinju 52727, Republic of Korea

E-mail: hyejungkim@gnu.ac.kr

Dr Bae Kwon Jeong, Department of Radiation Oncology, School of Medicine, Institute of Health Sciences, Gyeongsang National University, 816 Beongil 15 Jinjudaero, Jinju 52727, Republic of Korea E-mail: blue129j@gnu.ac.kr

Abbreviations: ALDH1, aldehyde dehydrogenase 1; BCSC, breast cancer stem cell; BMDCs, bone marrow-derived dendritic cells; CAM, cell adhesion molecules; DAPI, 4',6-diamidino-2-phenylindole dihydrochloride; EC, endothelial cell; ECM, extracellular matrix; EMT, epithelial-mesenchymal transition; FBS, fetal bovine serum; SDS-PAGE, sodium dodecyl sulfate polyacrylamide gel electrophoresis; SEM, standard error of the mean; RT-R, radioresistant

Key words: adhesion molecules, cancer stem cell, chemotherapy resistance, epithelial-mesenchymal transition, invasiveness, radioresistant breast cancer cells
MDA-MB-231 cells exhibited the most increased protein levels of CSCs markers cluster of differentiation 44, Notch-4, octamer-binding transcription factor $3 / 4$ and aldehyde dehydrogenase 1, compared with RT-R-MCF-7 cells, suggesting highly metastatic breast cancer cells MDA-MB-231 produce more CSCs. RT-R-MDA-MB-231 cells increased intercellular adhesion molecule-1 and vascular cell adhesion molecule-1 levels, resulting in enhanced migration and adhesion to endothelial cells (ECs), and enhanced invasiveness through ECs by inducing matrix metalloproteinase-9, Snail-1 and $\beta$-catenin, and by downregulating E-cadherin compared with MDA-MB-231 cells. These results suggest that highly metastatic breast cancer cells may increase the number of CSCs following radiation therapy, and CSCs present in RT-R-MDA-MB-231 cells contribute to the enhanced invasiveness by increasing migration, adhesion to ECs and invasion through ECs by promoting epithelial-mesenchymal transition (EMT) via the upregulation of adhesion molecules and EMT-associated proteins.

\section{Introduction}

Cancer is a leading cause of mortality worldwide, and breast cancer is one of the most common causes of cancer-associated mortality in females (1). The majority of patients with breast cancer respond to conventional therapies, including surgical removal of the tumor, drug treatment and radiation. However, each therapy has inherent limitations that lead to therapeutic resistance and disease recurrence, ultimately resulting in therapeutic failure. Once the disease recurs, it readily metastasizes to distant organs and causes mortality.

Cancer metastasis is the process by which cancer cells spread from the site of origin to grow in adjacent sites and is responsible for the majority of cancer-associated mortalities rather than the primary tumor (2-4). It has been suggested that cancer stem cells (CSCs) exist in tumors, and contribute to metastasis to distant organs and disease recurrence $(5,6)$. CSCs are capable of self-renewal and of regenerating the heterogeneous populations that comprise a tumor following treatment (7). Some or all of such cells in a tumor may exist in specific microenvironments that render them more resistant 
to radiotherapy and chemotherapy, ultimately resulting in tumor recurrence and distant metastasis (8-12). The presence of CSCs in breast tumors is known to increase post-therapy recurrence or relapse in patients with breast cancer, but the underlying mechanisms of therapy resistance remains unclear.

The radioresistance of breast cancer cells remains a fundamental barrier to the maximum efficacy of radiotherapy, raising the needs for the study of development of resistance by the breast cancer cells to radiation. Therefore, in the present study, we hypothesized that highly metastatic breast cancer cells MDA-MB-231 cells produce more CSCs following exposure to radiation, and accordingly, radioresistant (RT-R) breast cancer cells derived from highly metastatic breast cancer cells enhance invasiveness due to CSCs. Furthermore, the present study aimed to investigate the potential associated mechanisms underlying the involvement of CSCs in RT-R-MDA-MB-231 cell invasiveness under tumor microenvironment conditions.

\section{Materials and methods}

Cell culture. The human breast cancer cell lines, MCF-7, T47D and MDA-MB-231, were obtained from the Korea Cell Line Bank (Seoul, Korea), and the EA.hy926 human umbilical vascular endothelial cell (EC) line was originally purchased from American Type Culture Collection (Manassas, VA, USA). The human breast cancer cell lines and EA.hy926 cells were cultured in RPMI-1640 and Dulbecco's modified Eagle's medium, respectively, and supplemented with 10\% FBS, $100 \mathrm{IU} / \mathrm{ml}$ penicillin and $10 \mu \mathrm{g} / \mathrm{ml}$ streptomycin (all from HyClone; GE Healthcare Life Sciences, Logan, UT, USA). Cells were incubated at $37^{\circ} \mathrm{C}$ in a humidified atmosphere containing $5 \% \mathrm{CO}_{2}$.

Establishment of RT-R breast cancer cells. RT-R breast cancer cells (RT-R-MCF-7, RT-R-T47D and RT-R-MDA-MB-231 cells) were generated by applying repetitive small doses of X-ray irradiation (2 Gy) until a final dose of 50 Gy was achieved, which is a commonly used clinical regimen for the radiotherapy of patients with breast cancer. Cells were irradiated with 2 Gy using a 6-MV photon beam produced by a linear accelerator (Clinac 21EX, Varian Medical Systems, Inc., Palo Alto, CA). The radiation dose rate was $1.0 \mathrm{~Gy} / \mathrm{min}$, and the cell medium was changed to fresh complete media immediately following irradiation. When the cells reached $\sim 90 \%$ confluence, they were trypsinized and subcultured into new flasks. When the cells reached $\sim 70 \%$ confluence, they were irradiated again. The fractionated irradiations were continued until the total dose reached $50 \mathrm{~Gy}$.

Cell viability assay. Cells in the exponential growth phase were seeded at $1 \times 10^{4}$ cells/well in 24 -well plates. Cells were irradiated $(2,4,6$ or $8 \mathrm{~Gy})$ or treated with paclitaxel (Sigma-Aldrich; Merck KGaA, Darmstadt, Germany; 0.01, $0.05,0.1,1$ or $5 \mathrm{mM}$ ) as indicated. Control groups were not irradiated or not treated with paclitaxel, respectively. Then, $50 \mu \mathrm{l}$ of $5 \mathrm{mg} / \mathrm{ml}$ MTT (Sigma-Aldrich; Merck KGaA) was added, and the cells were incubated for $4 \mathrm{~h}$. The supernatants were aspirated, and the formazan crystals were dissolved with
$200 \mu \mathrm{l} /$ well DMSO. The absorbance was measured at $570 \mathrm{~nm}$ using an Infinite 200 microplate reader (Tecan Group, Ltd., Mannedorf, Switzerland).

Colony formation assay. Parental breast cancer cells or RT-R-breast cancer cells were seeded in 6-well plates $\left(1 \times 10^{3}\right.$ cells/well). Then, cells were irradiated even doses from 2 to $8 \mathrm{~Gy}$ and incubated at $37^{\circ} \mathrm{C}$. Control groups were not irradiated. After 10 days (for MDA-MB-231/RT-R-MDA-MB231 and MCF-7/RT-R-MDA-MB-231) or after 14 days (for T47D/RT-R-T47D cells), the medium was discarded and each well was washed with PBS. The colonies were fixed in $100 \%$ methanol for $10 \mathrm{~min}$ at room temperature and then stained with $0.1 \%$ Giemsa staining solution for $30 \mathrm{~min}$ at room temperature, and the number of visible colonies was counted.

Flow cytometry. For analysis of cluster of differentiation (CD)24 and CD44 expression or population, the cells were labeled using a human CD24 (cat. no. ab31622; 1:100; Abcam, Cambridge, UK) and CD44 (cat. no. ab5107; 1:100; Abcam) detection antibodies in PBS in the dark for $30 \mathrm{~min}$ at room temperature. Then, the cells were washed with cold PBS and analyzed using a FACSCalibur ${ }^{\mathrm{TM}}$ system with CellQuest Pro $^{\mathrm{TM}}$ software (version 3.0; BD Biosciences, Franklin Lakes, NJ, USA).

Isolation of CD24 $4^{\text {low }} / C D 44^{\text {high }}$ cancer stem cells from breast cancer cells. Isolation of $\mathrm{CD} 24^{\text {low }} / \mathrm{CD} 44^{\text {high }}$ breast cancer stem cells was performed using a MagCollect CD24- CD44+ Breast Cancer Stem Cell Isolation kit (R\&D Systems, Inc., Minneapolis, MN, USA) following the manufacturer's protocol.

Western blot analysis. Western blot analysis was performed as described previously (13), with minor modifications. The membranes were blocked with $5 \%$ non-fat milk in TBS containing $0.05 \%$ Tween-20 for $1 \mathrm{~h}$ at room temperature, and incubated with the following primary antibodies overnight at $4^{\circ} \mathrm{C}$ : Anti-intercellular adhesion molecule-1 (ICAM-1; cat. no. sc-7891; 1:1,000; rabbit polyclonal $\mathrm{IgG}$ ), anti-vascular cell adhesion molecule-1 (VCAM-1; cat. no. sc-8304; 1:1,000; rabbit polyclonal IgG), anti-Snail 1 (cat. no. sc-5594; 1:1,000; rabbit polyclonal $\mathrm{IgG}$ ), anti- $\beta$-catenin (cat. no. sc-7199; 1:1,000; rabbit polyclonal IgG), anti-E-cadherin (cat. no. sc-7870; 1:1,000; rabbit polyclonal $\mathrm{IgG}$ ), anti-N-cadherin (cat. no. sc-7939; 1:1,000; rabbit polyclonal $\mathrm{IgG}$ ), anti-octamer-binding transcription factor (Oct3/4; cat. no. sc-9081; 1:1,000; rabbit polyclonal IgG), anti-Notch-4 antibodies (cat. no. H-225; 1:1,000; rabbit polyclonal IgG) (all from Santa Cruz Biotechnology, Inc. Dallas, TX, USA) and anti-aldehyde dehydrogenase 1 (ALDH1; cat. no. ab52492; 1:1,000; rabbit monoclonal; Abcam). The bound antibodies were detected with goat anti-rabbit IgG-horseradish peroxidase-conjugated secondary antibodies (cat. no. sc-2054; 1:5,000; Santa Cruz Biotechnology, Inc.) for $1 \mathrm{~h}$ at room temperature and ECL western blotting detection reagent (Bio-Rad Laboratiories, Inc., Hercules, CA, USA). The protein band densities was analyzed using a ChemiDoc ${ }^{\mathrm{TM}}$ $\mathrm{XRS}+$ system (Bio-Rad Laboratiories, Inc.) and $\beta$-actin (cat. no. a2066; 1:1,000; rabbit monoclonal; Sigma-Aldrich; 
Merck KGaA) was used as a loading control for the normalization of protein expression.

Adhesion assay. MDA-MB-231 and RT-R-MDA-MB-231 cells $\left(4.0 \times 10^{5}\right.$ cells $\left./ \mathrm{ml}\right)$ were added to the ECs once $\sim 80 \%$ confluence was achieved. After $30 \mathrm{~min}$ at $37^{\circ} \mathrm{C}$, the cell suspensions were removed, and the ECs were washed three times with PBS. The cells were then counted under a light microscope (x200 magnification), and the number of cells that adhered to the ECs was quantified.

Migration assay. The migration assay was performed as described previously (14). Briefly, MDA-MB-231 and RT-R-MDA-MB-231 cells $\left(2 \times 10^{5}\right.$ cells/well) were added to the upper chambers of the inserts, which were placed in a 24-well plate, and $500 \mu \mathrm{l} /$ well RPMI-1640 supplemented with $10 \%$ FBS was added to the lower chambers. Following an overnight, the non-migratory cells that remained on the upper surface of the insert membranes were removed by swabbing. The cells that had migrated across the membrane were stained with DAPI for $30 \mathrm{~min}$ at room temperature in the dark, and the cells were counted under a fluorescence microscope (x200 magnification).

Matrigel invasion assay. The upper chambers of the inserts were coated with $100 \mu \mathrm{l}$ of Matrigel ( $1 \mathrm{mg} / \mathrm{ml}$, BD Bioscience), and ECs $\left(2 \times 10^{5}\right.$ cells $)$ were added to the Matrigel-coated insert. MDA-MB-231 cells and RT-R-MDA-MB-231 cells $\left(2 \times 10^{5}\right.$ cells/insert) were added to the upper chambers in serum-free media, and $500 \mu 1$ of RPMI-1640 supplemented with $10 \%$ FBS was added to the lower chambers. The remaining procedures were performed as aforementioned for the migration assays.

Gelatin zymography. A total of $2 \mathrm{ml}$ of media were collected from cultured MDA-MB-231 cells or RT-R-MDA-MB-231 cells and concentrated by 20 -fold using protein concentrators (9K MWCO; Thermo Fisher Scientific, Inc., Waltham, MA, USA). Concentrated media (40 mg protein in $20 \mathrm{ml} / \mathrm{lane}$ ) was mixed with sample volume of buffer $(0.03 \%$ bromophenol blue, 0.4 M Tris- $\mathrm{HCl}$ pH 7.4, 20\% glycerol, 5\% SDS), and then subjected to electrophoresis on $8 \%$ PAGE gels containing $1 \mathrm{mg} / \mathrm{ml}$ gelatin. The gels were washed with renaturing buffer (2.5\% Triton X-100) for $1 \mathrm{~h}$ and subsequently incubated for $24 \mathrm{~h}$ at $37^{\circ} \mathrm{C}$ in developing buffer $(50 \mathrm{mM}$ Tris, $20 \mathrm{mM} \mathrm{NaCl}, 5 \mathrm{mM} \mathrm{CaCl}_{2}, 0.02 \%$ Brij35, pH 7.5). Gels were stained with $0.05 \%$ Coomassie Brilliant Blue R-250 and destained with $50 \%$ methanol and $10 \%$ acetic acid for $2 \mathrm{~h}$ at room temperature. Within the blue background, clear zones indicated matrix metalloproteinase (MMP) proteolytic activity.

Statistical analysis. All results are representative of three independent experiments performed in triplicate. The statistics were determined using SigmaPlot software (version 10.0; Systat Software, Inc., San Jose, CA, USA). The data were analyzed with two-tailed Student's t-test to compare two groups or one-way analysis of variance with Scheffe's post hoc test to compare mean values across multiple treatment groups. The data are presented as the mean \pm standard error.

\section{Results}

$R T-R$ breast cancer cells established by repeated irradiation demonstrate resistance to chemotherapy and radiation. First, cell viability of established RT-R-breast cancer cells was examined using MTT assay following exposure to fractionated irradiation (2, 4, 6 or 8 Gy). Irradiated parental MCF-7, MDA-MB-231 and T47D cells demonstrated survival rates of $\sim 60, \sim 67$ and $\sim 64 \%$ relative to non-irradiated MCF-7, MDA-MB-231 and T47D cells, respectively. However, RT-R-breast cancer cells exhibited $\sim 20, \sim 50$ and $\sim 60 \%$ greater resistance compared with parental MCF-7, MDA-MB-231 and T47D cells, respectively (Fig. 1A). In addition, fractionated irradiation (2, 4, 6 or 8 Gy) of parental MCF-7, MDA-MB-231 and T47D breast cancer cells caused a significant decrease in colony formation compared with non-irradiated MCF-7, MDA-MB-231 and T47D cells (Fig. 1B). Then, the cross resistance of RT-R-breast cancer cells was examined via incubation of cells with paclitaxel at $0.01-5 \mathrm{mM}$ for 24 and $48 \mathrm{~h}$. Paclitaxel treatment significantly decreased the cell viability of the three breast cancer cell lines compared with the untreated control group in a dose-dependent manner (Fig. 1C), but RT-R-breast cancer cells except RT-R-MDA-MB-231 demonstrated almost no difference on cytotoxicity compared with their parental breast cancer cells. RT-R-MDA-MB-231 cells demonstrated the strongest resistance to paclitaxel particularly following treatment for $48 \mathrm{~h}$ (Fig. 1C), suggesting that RT-R-MDA-MB-231 cells derived from highly metastatic breast cancer cells MDA-MB-231 may become more resistant to chemotherapy as well as radiation, compared with other RT-R-breast cancer cells from low metastatic MCF-7 or T47D breast cancer cells.

RT-R-MDA-MB-231 cells demonstrate higher levels of CSCs markers CD44, but lower levels of CD24, compared with MDA-MB-231 or RT-R-MCF-7 cells. It has been suggested that CSCs represent a possible cause of tumor resistance to irradiation as well as chemotherapy (15-17). Therefore, whether RT-R-MDA-MB-231 cells harbored more CSCs compared with MDA-MB-231 cells or RT-R-MCF-7 cells derived from the low metastatic breast cancer cells MCF-7 was investigated. When the expression levels of CD24 and CD44 were examined by western blot analysis, RT-R-MCF-7 and RT-R-MDA-MB-231 cells revealed significantly higher expression levels of CD44 and lower expression levels of CD24 (Fig. 2), compared with MCF-7 and MDA-MB-231 cells, respectively. RT-R-MDA-MB-231 and RT-R-MCF-7 cells expressed a significantly higher level of CD44 compared with MDA-MB-231 cells ( 2-fold) and MCF-7 cells ( 1.5-fold), respectively, indicating that RT-R-MDA-MB-231 cells possessed a higher number of CSCs compared with RT-R-MCF-7 cells. This result supports the idea that RT-R-MDA-MB-231 cells derived from highly metastatic breast cancer cells MDA-MB-231 are more resistant, compared with RT-R-MCF-7 cells derived from low metastatic breast cancer cells MCF-7, due to the level of CSCs present.

RT-R-MDA-MB-231 cells increase the number of $C D 24^{\text {low }} / C D 44^{\text {high }}$ cells and expression levels of CSCs 

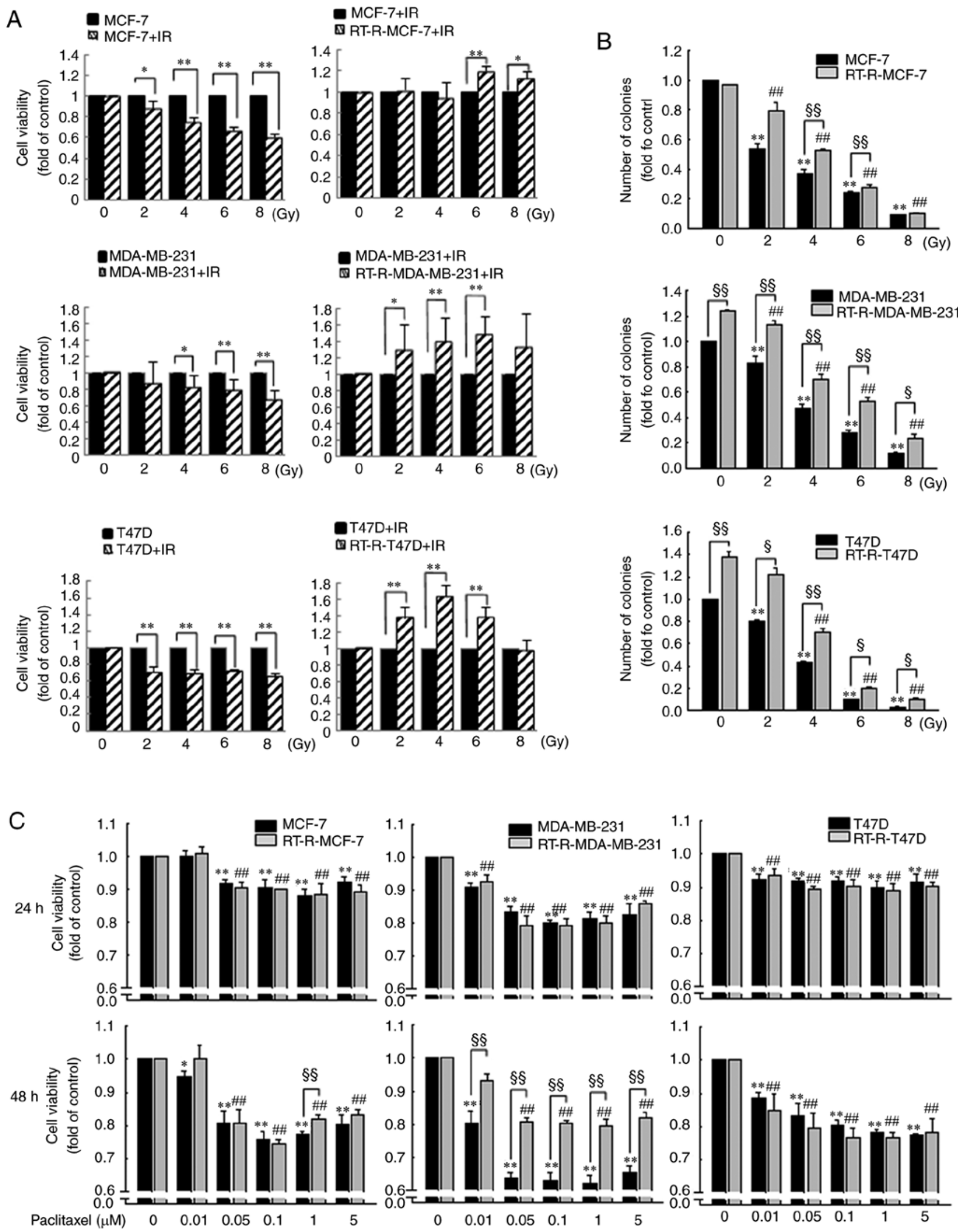

Figure 1. Radioresistant breast cancer cells established by repeated irradiation exhibit resistance to radiation and chemotherapy. (A) The viabilities of MCF-7, RT-R-MCF-7, MDA-MB-231, RT-R-MDA-MB-231, T47D and RT-R-T47D cells against radiation treatment (2, 4, 6, 8 Gy) were examined as described in the Materials and methods. ${ }^{*} \mathrm{P}<0.05,{ }^{* *} \mathrm{P}<0.01$. (B) Parental breast cancer cells (MCF-7, T47D and MDA-MB-231 cells) or RT-R-breast cancer cells (RT-R-MCF-7, RT-R-T47D, RT-R-MDA-MB-231 cells) were irradiated (2, 4, 6, 8 Gy), and then colony formation assays were performed. (C) Parental and RT-R-breast cancer cells were treated with paclitaxel at the indicated doses $(0.01-5 \mathrm{mM})$ for 24 and $48 \mathrm{~h}$. Cell viability was determined and compared with the untreated control groups. Data represent mean values \pm standard error of the mean of three independent experiments in triplicate. ${ }^{* *} \mathrm{P}<0.01$ compared with parental breast cancer control cells; ${ }^{\# \#} \mathrm{P}<0.01$ compared with RT-R-breast cancer control cells; ${ }^{\S} \mathrm{P}<0.05$ and ${ }^{\S \S} \mathrm{P}<0.01$ compared between parental breast cancer cells and RT-R-breast cancer cells. IR, irradiation; RT-R, radioresistant. 

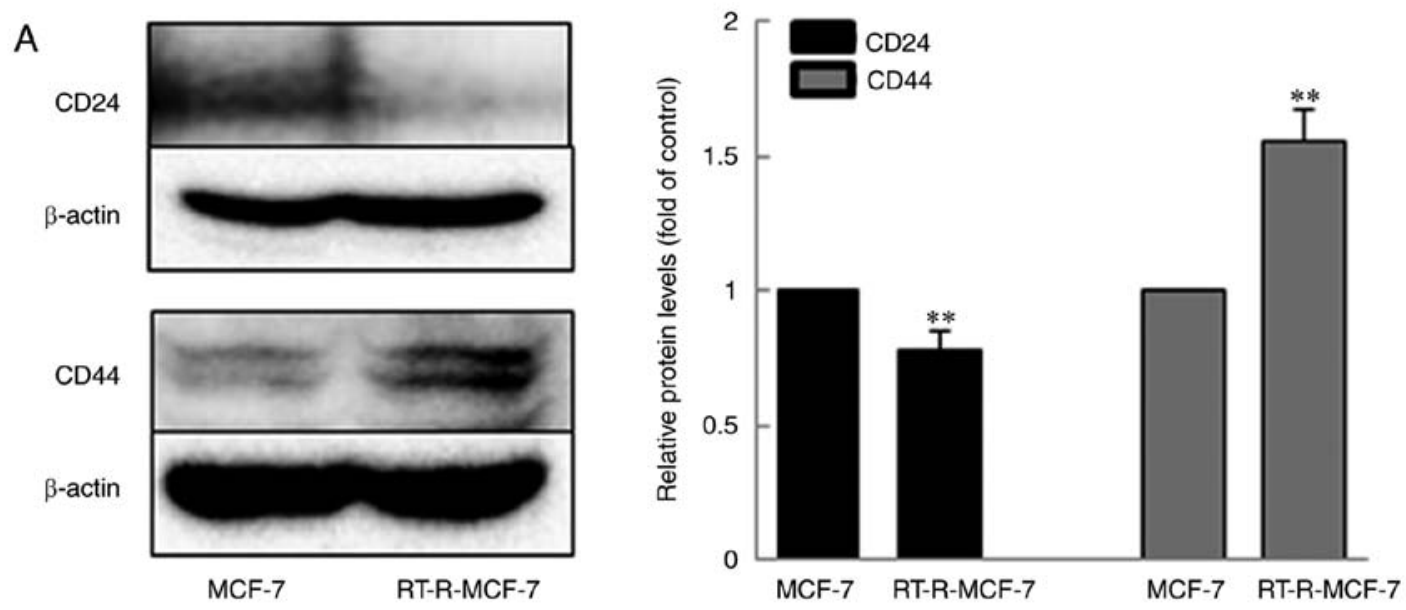

B
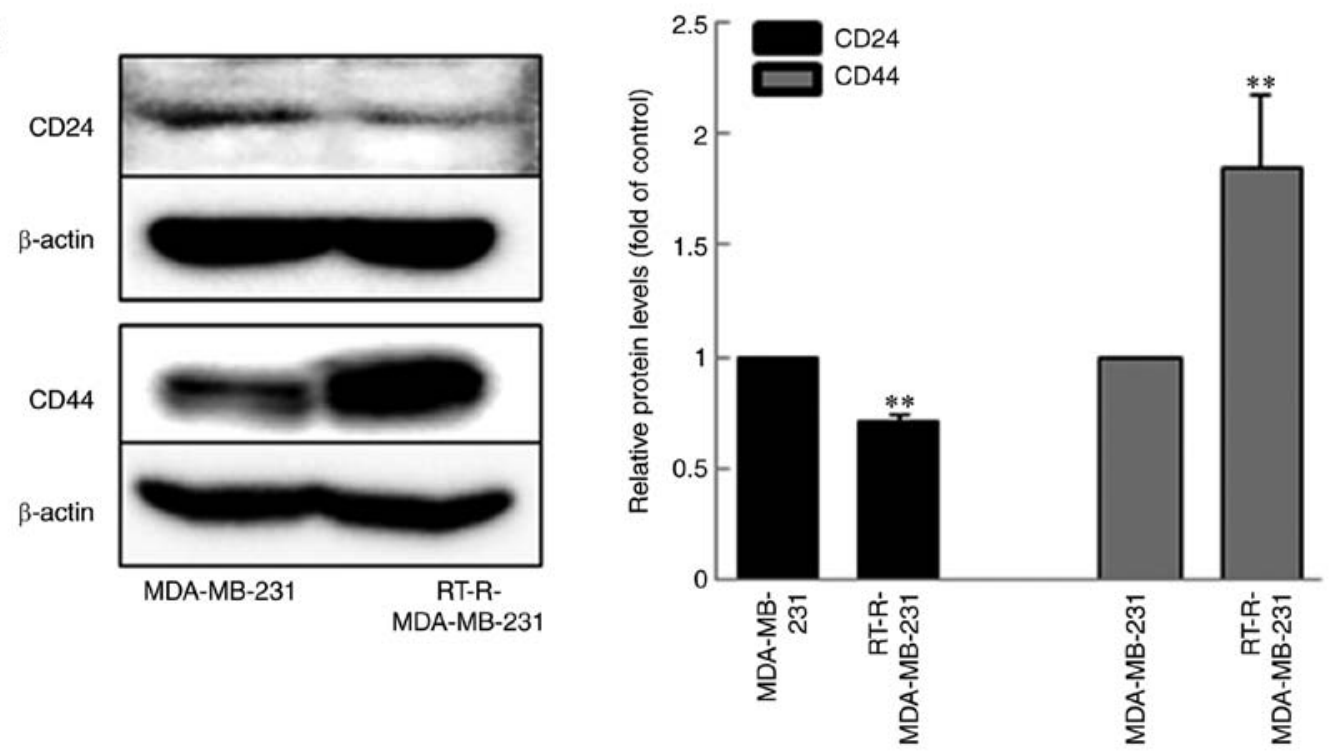

Figure 2. RT-R-MDA-MB-231 cells demonstrate higher levels of CSCs marker CD44, but lower levels of CD24 compared with MDA-MB-231 cells. Classical CSCs markers CD44 and CD24 were detected in the low metastatic breast cancer cells MCF-7 and RT-R-MCF-7 (A) and highly metastatic breast cancer cells MDA-MB-231 and RT-R-MDA-MB-231 (B) using the specific antibodies by western blotting. Data represent mean values \pm standard error of the mean of three independent experiments in triplicate. ${ }^{* *} \mathrm{P}<0.01$ compared with control. $\mathrm{CD}$, cluster of differentiation; CSCs, cancer stem cells; RT-R, radioresistant.

markers Notch-4, Oct-3/4 and ALDH1 compared with $M D A-M B-231$ cells. According to the aforementioned results, RT-R-MDA-MB-231 cells were chosen to investigate the role of CSCs in the increased invasiveness of RT-R-breast cancer cells and the potential underlying mechanisms. First of all, CD24 ${ }^{\text {low }} / C D 44^{\text {high }}$ cells were isolated from MDA-MB-231 and RT-R-MDA-MB cells using isolation kit as aforementioned, which confirmed that the number of the isolated CD24 $4^{\text {low }} / \mathrm{CD} 44^{\text {high }}$ cells from RT-R-MDA-MB-231 cells was significantly higher compared with MDA-MB-231 cells, as indicated by flow cytometric analysis (Fig. 3A). Then, the expression levels of CD24 or CD44 were analyzed by flow cytometry, and other CSC markers, including Notch-4, Oct-3/4 and ALDH1 (18-22) were determined using western blot analysis. Fig. 3B demonstrates that RT-R-MDA-MB-231 cells exhibited significantly higher CD44 and lower CD24 levels compared with MDA-MB-231 cells. The CSC markers, Notch-4, Oct3/4 and ALDH1, were also significantly upregulated in RT-R-MDA-MB-231 cells compared withMDA-MB-231 cells (Fig. 3C).
RT-R-MDA-MB-231 cells demonstrate higher expression levels of adhesion molecules (AMs) and epithelial-mesenchymal transition (EMT)-associated proteins, resulting in enhanced migration, adhesion to ECs and invasion through ECs compared with MDA-MB-231 cells. We previously reported that induction of AMs by MDA-MB-231 serves an important role in cancer cell migration, cancer cell adhesion to ECs and cancer cell invasion through ECs (14). Thus, whether RT-R-MDA-MB-231 cells exhibited higher expression of AMs, including ICAM-1 and VCAM-1, was examined. ICAM-1 and VCAM-1 expression was significantly increased in RT-R-MDA-MB-231 cells compared with MDA-MB-231 cells (Fig. 4). Next, adhesion and migration assays were performed. As expected, RT-MDA-MB-231 cells exhibited significantly enhanced migration and adhesion to ECs compared with MDA-MB-231 cells (Fig. 4B and C). Furthermore, the invasiveness was significantly enhanced in RT-R-MDA-MB-231 cells compared with MDA-MB-231 cells (Fig. 4D). Next, the expression levels of EMT markers were determined in RT-R-MDA-MB-231 cells. Fig. 5A and B demonstrates that 
A

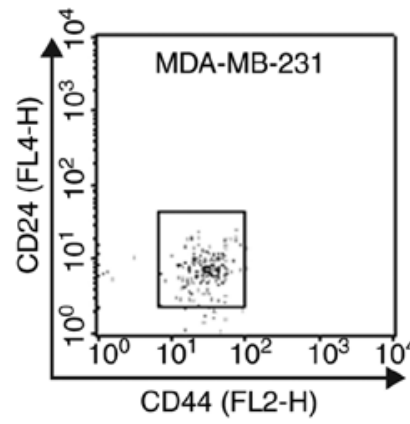

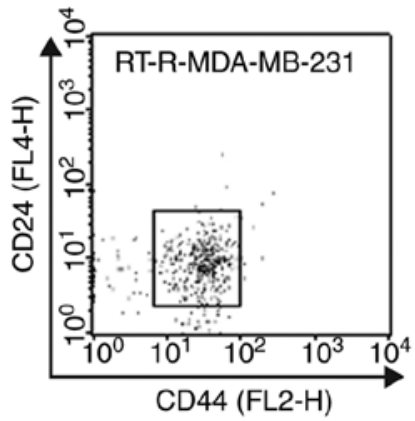
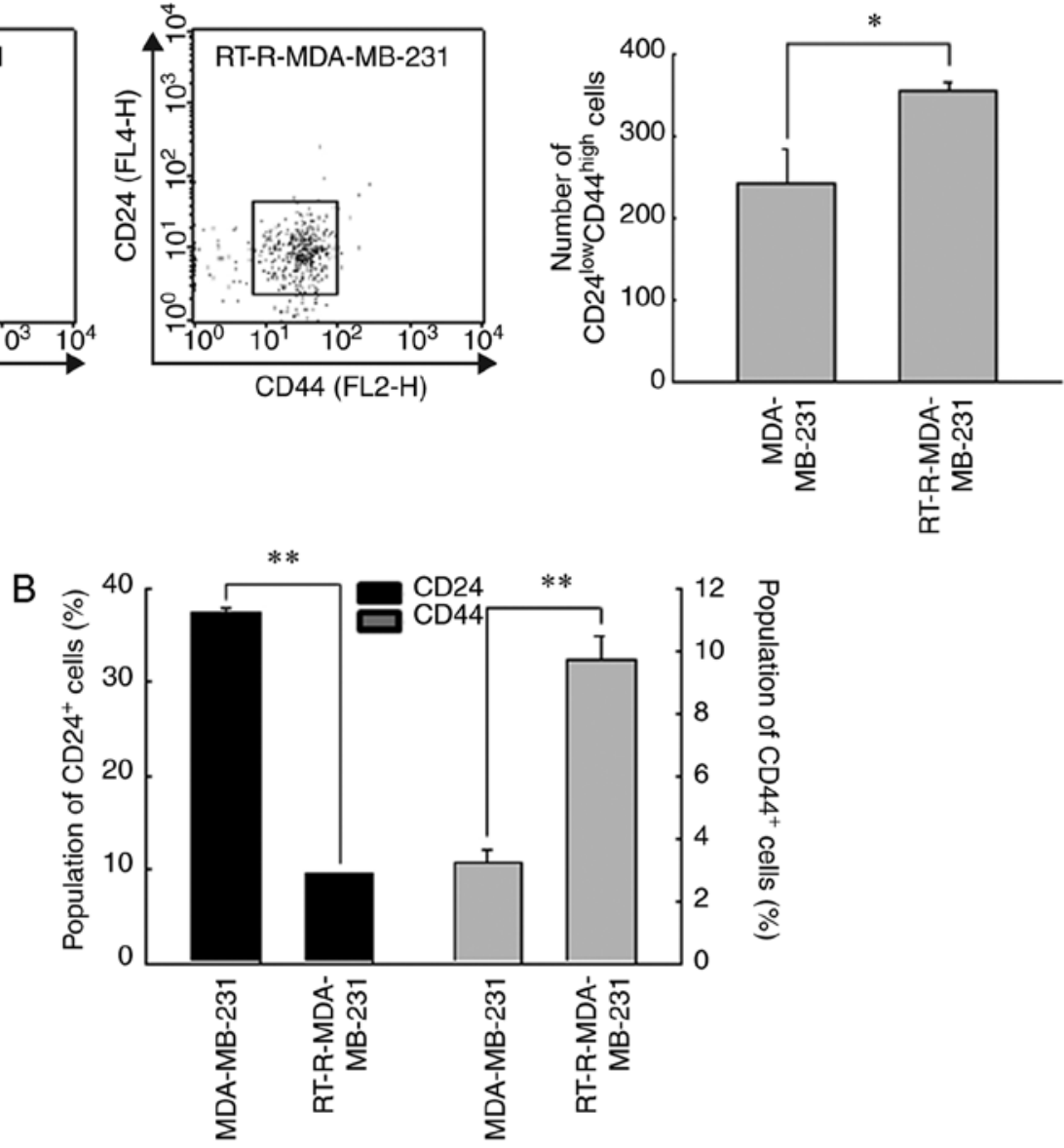
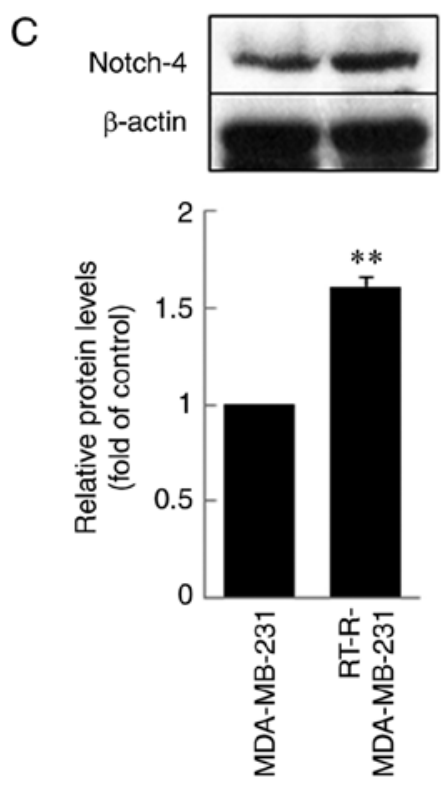
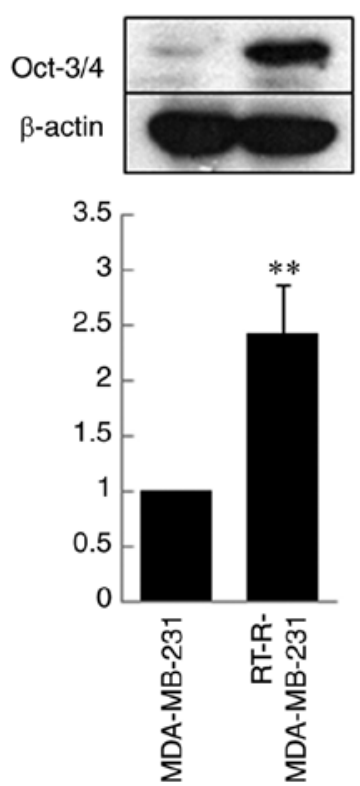
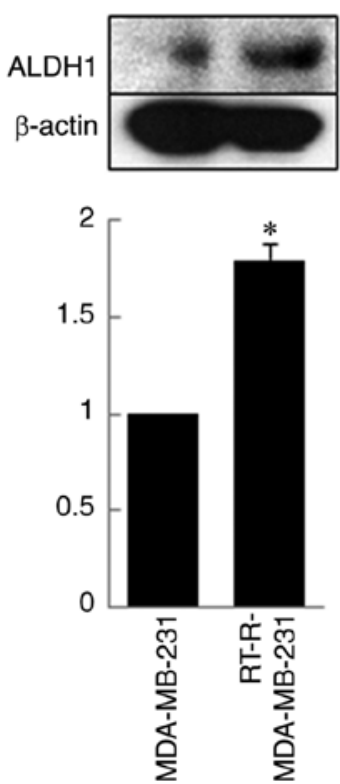

Figure 3. RT-R-MDA-MB-231 cells increase the populations of CD24 $4^{\text {low }} / \mathrm{CD} 44^{\text {high }}$ cells, and expression levels of other CSCs markers Notch-4, Oct-3/4 and ALDH1. (A) CD24 ${ }^{\text {low }} / C D 44^{\text {high }}$ cells were isolated from MDA-MB-231 and RT-R-MDA-MB cells, and then the number of CD24 $4^{\text {low }} / C D 44^{\text {high }}$ breast cancer stem cells was quantified by flow cytometry. (B) MDA-MB-231 and RT-R-MDA-MB-231 were labeled with anti-CD24 and anti-CD44 antibodies, and the percentages of CD24 or CD44-expressed subpopulation in cells were determined by flow cytometry. (C) Other cancer stem cell markers, including Notch-4, Oct3/4 and ALDH1 were detected in the MDA-MB-231 and RT-R-MDA-MB-231 cells using the specific antibodies by western blotting. Data represent mean values \pm standard error of the mean of three independent experiments in triplicate. " $\mathrm{P}<0.05$ and ${ }^{* *} \mathrm{P}<0.01$ compared with MDA-MB-231 cells. ALDH1, aldehyde dehydrogenase 1; CD, cluster of differentiation; CSCs, cancer stem cells; Oct, octamer-binding transcription factor; RT-R, radioresistant.

RT-R-MDA-MB-231 cells significantly upregulated the activity of MMP-9, and the expression of the mesenchymal markers Snail and $\beta$-catenin, but downregulated the expression of the epithelial marker E-cadherin. These results suggest that RT-R-MDA-MB-231 cells increased the invasiveness of cells by upregulating EMT-associated protein and AM expression. 
A
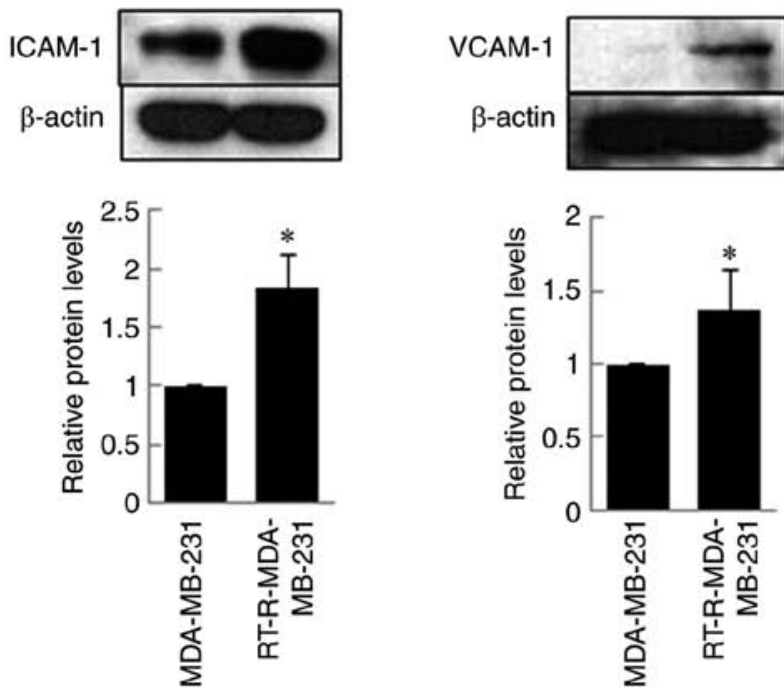

B

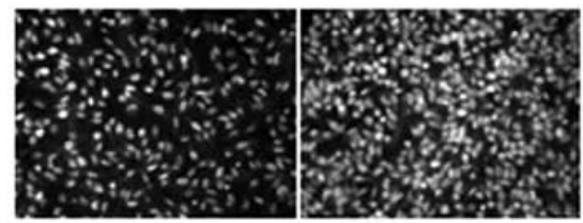

C
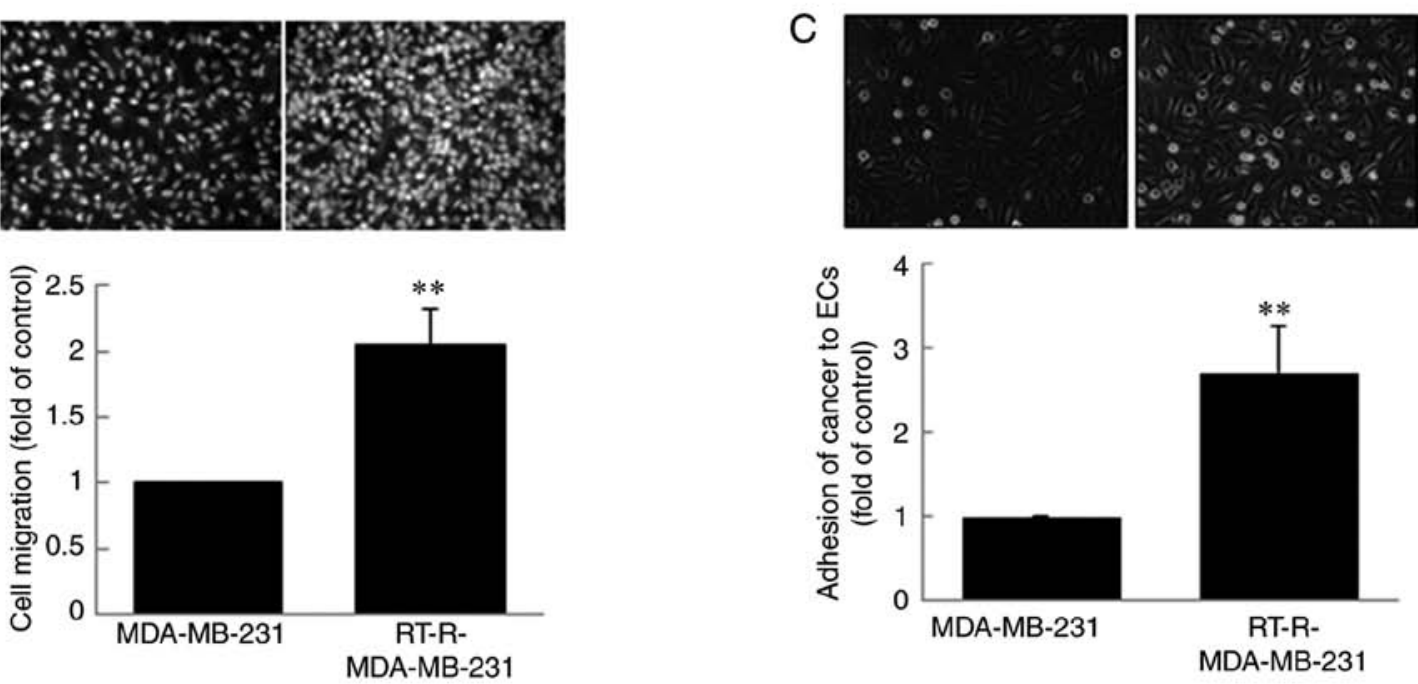

D

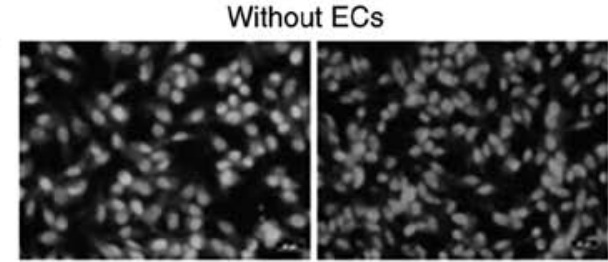

With EC
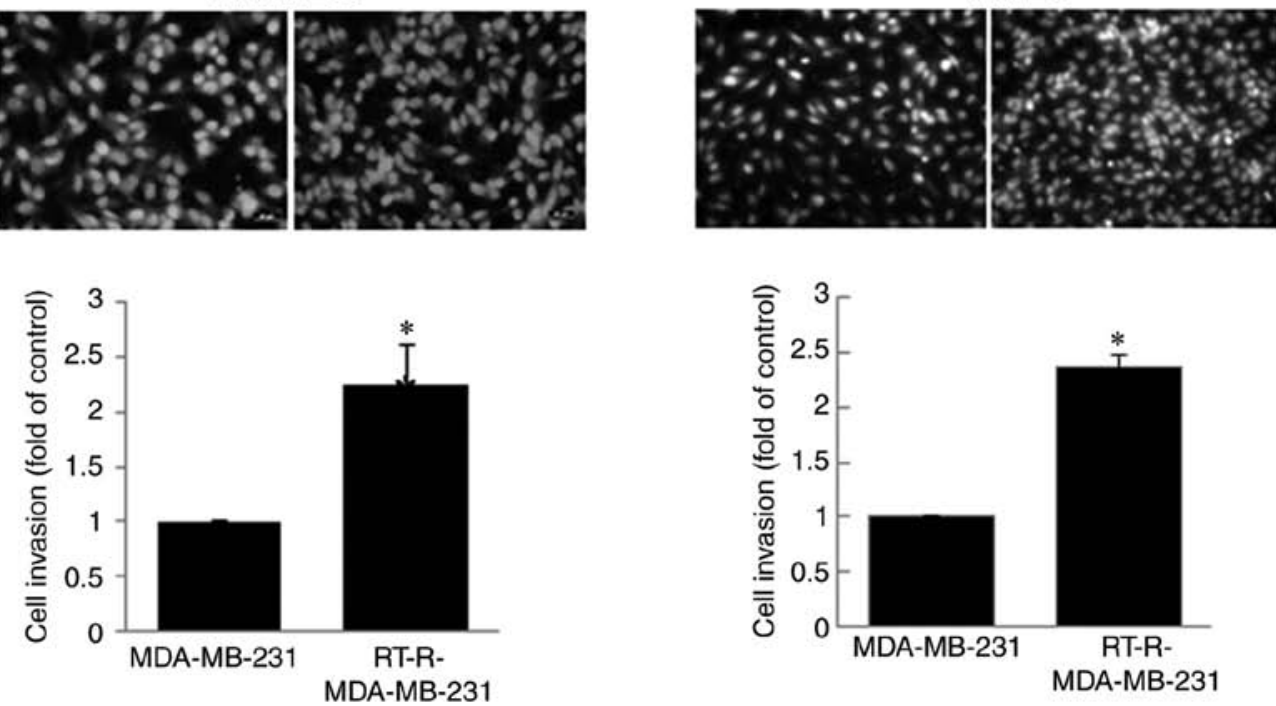

Figure 4. RT-R-MDA-MB-231 cells exhibit higher expression levels of ICAM-1 and VCAM-1, resulting in enhanced migration, adhesion to ECs and invasion through ECs. (A) Protein was extracted from the cells, and western blotting was performed to detect ICAM-1 and VCAM-1 expression. (B) MDA-MB-231 and RT-R-MDA-MB-231 cells were seeded into cell culture inserts. After $24 \mathrm{~h}$, the cancer cells that had migrated across the insert well membrane were stained with DAPI, counted under a fluorescence microscope and quantified (x200 magnification). (C) MDA-MB-231 and RT-R-MDA-MB-231 cells were cultured with ECs. After $30 \mathrm{~min}$, the remaining cell suspension was withdrawn, and the number of adherent cells was counted under a light microscope and quantified (x200 magnification). (D) MDA-MB-231 and RT-R-MDA-MB-231 cells were seeded onto the Matrigel-coated insert wells or EC-Matrigel-coated insert wells in serum-free media, and the rest of the procedure was performed as described for the Migration assay. Data represent mean values \pm standard error of the mean of three independent experiments. ${ }^{*} \mathrm{P}<0.05$ and ${ }^{* *} \mathrm{P}<0.01$ compared with MDA-MB-231 cells. EC, endothelial cell; ICAM-1, intercellular adhesion molecule-1; RT-R, radioresistant; VCAM-1, vascular cell adhesion molecule-1. 


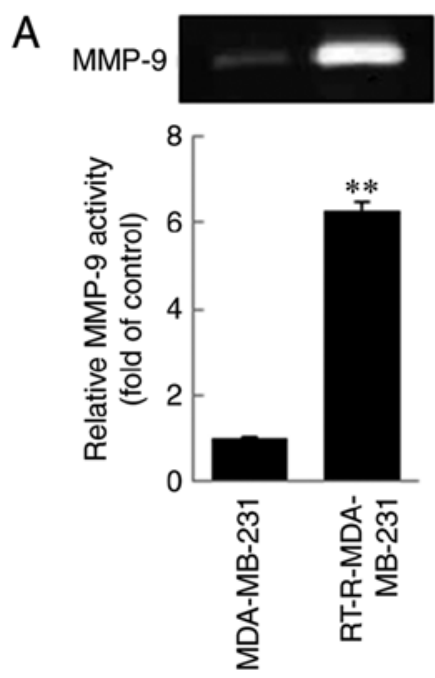

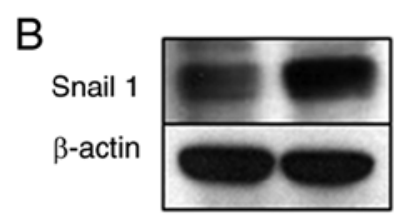

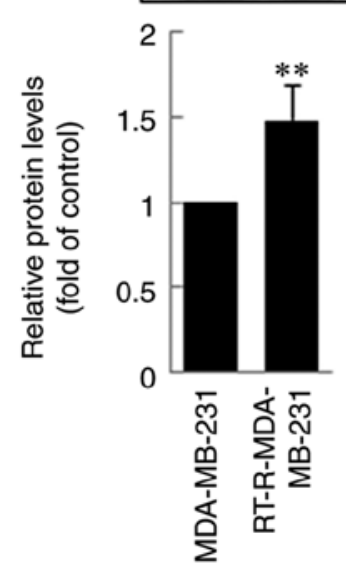

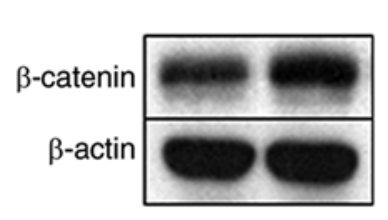

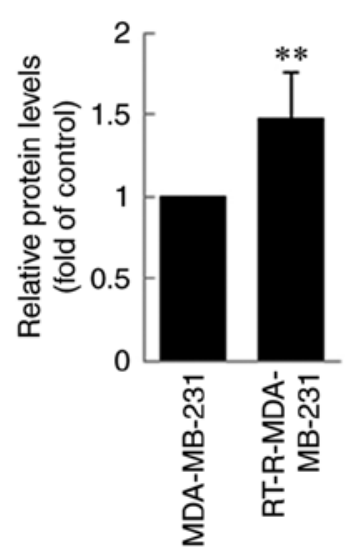

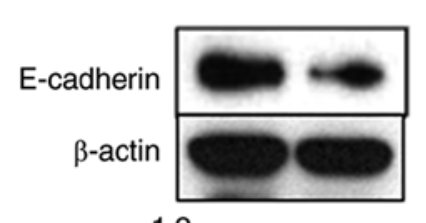
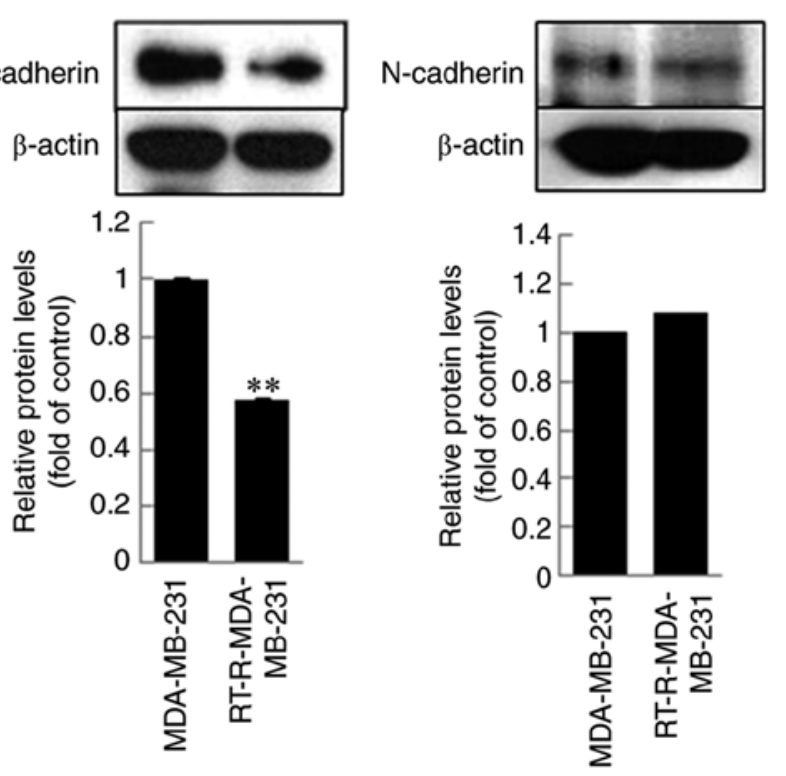

Figure 5. RT-R-MDA-MB-231 cells exhibit higher MMP-9 activity, and levels of EMT proteins, Snail-1 and $\beta$-catenin, but decreased levels of E-cadherin. (A) Cells were serum-starved overnight, and MMP gelatinase activities were determined from the conditioned media by zymography (MMP-9; 92 kDa). (B) Cell lysates were obtained from MDA-MB-231 and RT-R-MDA-MB-231 cells, and the protein levels of Snail, N-cadherin, E-cadherin and $\beta$-catenin were determined by western blot analysis. Data are presented as the mean values \pm standard error of the mean of three independent experiments. ${ }^{* *} \mathrm{P}<0.01$ compared with MDA-MB-231 cells. EMT, epithelial-mesenchymal transition; MMP-9, matrix metalloproteinase-9; RT-R, radioresistant.

\section{Discussion}

Radiotherapy is an important treatment option in modern cancer therapy besides surgery and systemic therapy; currently, $>60 \%$ of all patients with cancer receive radiotherapy $(1,23)$. Unfortunately, tumor recurrence following radiotherapy is common, with numerous causes for radiotherapy failure and cancer recurrence, including metastasis (23). One underlying cause of tumor radioresistance is the existence of CSCs $(13,15)$. Indeed, preclinical data suggest that breast CSCs are enriched following radiation and are particularly resistant to radiation (10), as well as potentially to other cancer therapies. Accordingly, the present study aimed to determine whether RT-R-MDA-MB-231 breast cancer cells, which are highly metastatic, harbor a larger CSC population, compared with other low metastatic breast cancer cells. In addition, the current study aimed to clarify whether CSCs, which exist among RT-R-MDA-MB-231 cells, are responsible for the increased invasiveness and resistance to cancer therapies, and if so, the possible mechanisms for this behavior.

In the present study, it was demonstrated that RT-RMDA-MB-231 derived fromhighlymetastatic breastcancercells expressed significantly higher levels of CD44 compared with low metastatic breast cancer MDA-MB-231 or RT-R-MCF-7 cells, and significantly increased the expression of other CSCs markers, including Notch, Oct3/4 and ALDH1. These results suggested that RT-R-MDA-MB-231 cells possessed more CSCs. In addition, the results revealed that RT-R-breast cancer cells, derived through repeated irradiation, exhibited significantly increased colony forming abilities compared with the parental breast cancer cells. Notably, RT-R-MDA-MB-231 cells were more resistant to paclitaxel treatment compared with RT-R-MCF-7 or RT-R-T47D cells. There is controversy regarding the use of ALDH1 as a breast CSCs marker. While 

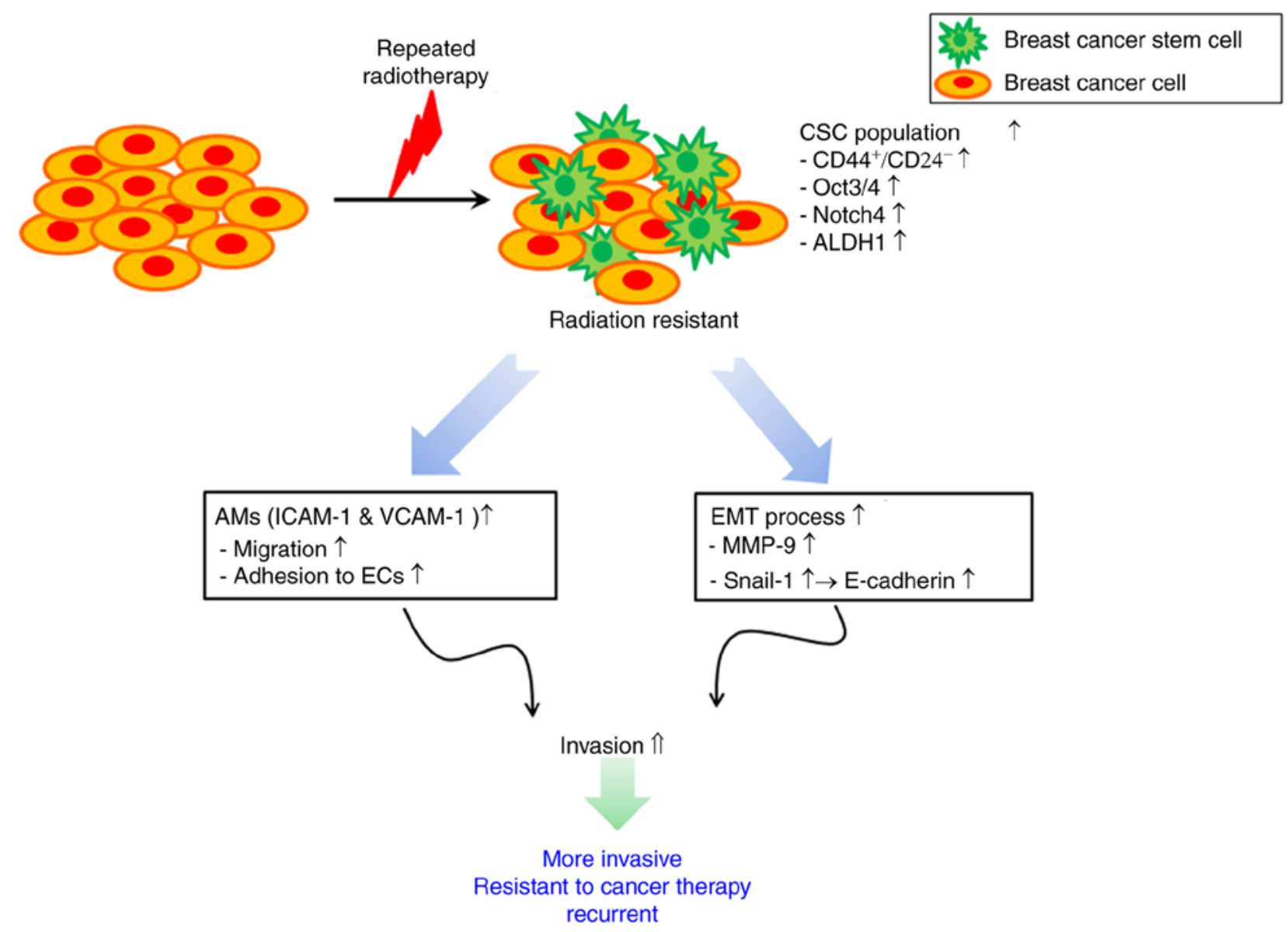

Figure 6. Schematic representation of the proposed role cancer stem cells on tumor growth and invasiveness in the radioresistant breast cancer cells. AM, adhesion molecule; ALDH1, aldehyde dehydrogenase 1; CD, cluster of differentiation; CSC, cancer stem cell; ECs, endothelial cells; EMT, epithelial-mesenchymal transition; ICAM-1, intercellular adhesion molecule-1; MMP, matrix metalloproteinase; Notch, neurogenic locus notch homolog; Oct, octamer-binding transcription factor; VCAM-1, vascular cell adhesion molecule-1.

Resetkova et al (24) reported that no significant increase in ALDH-1-positive cells following neoadjuvant chemotherapy in surgical specimens, other researchers (25-27), including Tanei et al (22) reported that ALDH1 was a more significant predictive marker compared with $\mathrm{CD} 44^{+} / \mathrm{CD} 24^{-}$for the identification of breast CSCs in terms of chemotherapy resistance. In the present study, ALDH1 levels were significantly increased in RT-R-MDA-MB-231 cells compared with MDA-MB-231 cells, and ALDH1 was not expressed in MCF-7 and T47D cells, even in RT-R-MCF-7 and RT-R-T47D cells (data not shown), suggesting that ALDH1 may be a potent marker of BCSCs, and ALDH1-positive breast CSCs may serve an important role in radioresistance.

As aforementioned, AMs, including ICAM-1 and VCAM-1, mediate cell migration and adhesion, resulting in cancer recurrence, invasion and the development of distant metastases. Thus, RT-R-MDA-MB-231 and MDA-MB-231 cells were compared in terms of AM expression, cell migration, adhesion to ECs and invasion through ECs. RT-R-MDA-MB-231 cells exhibited significantly increased expression of ICAM-1 and VCAM-1, resulting in enhanced migration and adhesion to ECs compared with MDA-MB-231 cells. In addition, RT-R-MDA-MB-231 cells demonstrated significantly increased invasion through ECs and expression of EMT-associated proteins, including MMP-9, Snail-1 and $\beta$-catenin. According to the reports,
MMPs are well known factors that mediate invasion through ECM remodeling $(28,29)$, and induction of EMT promotes tumor cell motility and invasion, potentially contributing to treatment resistance (30-34). In addition, it has been proposed that CSCs in primary tumors can metastasize to distant tissues or organs and form metastatic colonies via EMT (13). Therefore, it is suggested that CSCs in RT-R-MDA-MB-231 cells may promote invasion through AM expression and EMT induction.

Taken together, the results of the current study suggested that RT-R-breast cancer cells exhibited an increased population of CSCs. In particular, RT-R-MDA-MB-231 cells derived from highly metastatic breast cancer cells produced more CSCs, which leads to the acquisition of resistance to other cancer therapies besides radiotherapy. Furthermore, the results indicated the possible mechanisms for the increase in invasiveness of RT-R-MDA-MB-231 cells. CSCs that exist among RT-R-MDA-MB-231 cells contribute to enhanced invasiveness by increasing cancer cell migration, adhesion to ECs and invasion through ECs by promoting EMT via the upregulation of the expression of AMs and EMT-associated proteins (Fig. 6). Therefore, it is suggested that a multi-targeted approach against CSCs in combination with classic chemotherapy should be developed to reduce breast cancer resistance and relapse rates. 


\section{Acknowledgements}

Not applicable.

\section{Funding}

The present study was supported by Basic Science Research Program through the National Research Foundation of Korea funded by the Ministry of Education, Science and Technology (grant no. NRF-2015R1A1A3A04001029) and by the Ministry of Science, ICT and Future Planning (grant no. NRF-2015R1A5A2008833).

\section{Availability of data and materials}

The datasets used during the present study are available from the corresponding author upon reasonable request.

\section{Authors' contributions}

YSK performed the experiments and statistical analyses; HJ performed the experiments and revised the manuscript; JSL performed data analysis and helped with the interpretation of data; SWP and KCC analysed the data and revised the manuscript critically; KMK developed the methodology and discussed the data; BKJ designed the study, developed the methodology and directed the project; HJK designed the study, conceived the hypothesis, directed the project and wrote the manuscript.

\section{Ethics approval and consent to participate}

Not applicable.

\section{Patient consent for publication}

Not applicable.

\section{Competing interests}

The authors declare that they have no competing interests.

\section{References}

1. Torre LA, Bray F, Siegel RL, Ferlay J, Lortet-Tieulent J and Jemal A: Global cancer statistics, 2012. CA Cancer J Clin 65: 87-108, 2015.

2. Steeg PS: Tumor metastasis: Mechanistic insights and clinical challenges. Nat Med 12: 895-904, 2006.

3. Steeg PS: Cancer: Micromanagement of metastasis. Nature 449 671-673, 2007

4. Eccles SA and Welch DR: Metastasis: Recent discoveries and novel treatment strategies. Lancet 369: 1742-1757, 2007.

5. Clevers H: The cancer stem cell: Premises, promises and challenges. Nat Med 17: 313-319, 2011.

6. Sato R, Semba T, Saya H and Arima Y: Concise review: Stem cells and epithelial-mesenchymal transition in cancer: Biological implications and therapeutic targets. Stem Cells 34: 1997-2007, 2016.

7. Clarke MF, Dick JE, Dirks PB, Eaves CJ, Jamieson CH, Jones DL, Visvader J, Weissman IL and Wahl GM: Cancer stem cells-perspectives on current status and future directions: AACR workshop on cancer stem cells. Cancer Res 66: 9339-9344, 2006.

8. Bertolini G, Roz L, Perego P, Tortoreto M, Fontanella E, Gatti L, Pratesi G, Fabbri A, Andriani F, Tinelli S, et al: Highly tumorigenic lung cancer $\mathrm{CD} 133^{+}$cells display stem-like features and are spared by cisplatin treatment. Proc Natl Acad Sci USA 106: 16281-16286, 2009.
9. Creighton CJ, Li X, Landis M, Dixon JM, Neumeister VM, Sjolund A, Rimm DL, Wong H, Rodriguez A, HerschkowitzJI, et al: Residual breast cancers after conventional therapy display mesenchymal as well as tumor-initiating features. Proc Natl Acad Sci USA 106: 13820-13825, 2009.

10. Li X, Lewis MT, Huang J, Gutierrez C, Osborne CK, Wu MF, Hilsenbeck SG, Pavlick A, Zhang X, Chamness GC, et al: Intrinsic resistance of tumorigenic breast cancer cells to chemotherapy. J Natl Cancer Inst 100: 672-679, 2008.

11. Phillips TM, McBride WH and Pajonk F: The response of CD24(-/low)/CD44 ${ }^{+}$breast cancer-initiating cells to radiation. J Natl Cancer Inst 98: 1777-1785, 2006.

12. Abraham BK, Fritz P, McClellan M, Hauptvogel P, Athelogou M and Brauch $\mathrm{H}$ : Prevalence of $\mathrm{CD} 44^{+} / \mathrm{CD} 24^{-/ \text {low }}$ cells in breast cancer may not be associated with clinical outcome but may favor distant metastasis. Clin Cancer Res 11: 1154-1159, 2005.

13. Nizamutdinova IT, Lee GW, Lee JS, Cho MK, Son KH, Jeon SJ, Kang SS, Kim YS, Lee JH, Seo HG, et al: Tanshinone I suppreses growth and invasion of human breast cancer cells, MDA-MB-231, through regulation of adhesion molecules. Carcinogenesis 29: 1885-1892, 2008.

14. Jin H, Eun SY, Lee JS, Park SW, Lee JH, Chang KC and Kim HJ: $\mathrm{P} 2 \mathrm{Y} 2$ receptor activation by nucleotides released from highly metastatic breast cancer cells increases tumor growth and invasion via crosstalk with endothelial cells. Breast Cancer Res 16: R77, 2014.

15. Gupta PB, Chaffer CL and Weinberg RA: Cancer stem cells: Mirage or reality? Nat Med 15: 1010-1012, 2009.

16. Rosen JM and Jordan CT: The increasing complexity of the cancer stem cell paradigm. Science 324: 1670-1673, 2009.

17. Rycaj $K$ and Tang DG: Cancer stem cells and radioresistance. Int J Radiat Biol 90: 615-621, 2014.

18. Al-Hajj M, Wicha MS, Benito-Hernandez A, Morrison SJ and Clarke MF: Prospective identification of tumorigenic breast cancer cells. Proc Natl Acad Sci USA 100: 3983-3988, 2003.

19. Ponti D, Costa A, Zaffaroni N, Pratesi G, Petrangolini G, Coradini D, Pilotti S, Pierotti MA and Daidone MG: Isolation and in vitro propagation of tumorigenic breast cancer cells with stem/progenitor cell properties. Cancer Res 65: 5506-5511, 2005.

20. Koo BS, Lee SH, Kim JM, Huang S, Kim SH, Rho YS, Bae WJ, Kang HJ, Kim YS, Moon JH and Lim YC: Oct4 is a critical regulator of stemness in head and neck squamous carcinoma cells. Oncogene 34: 2317-2324, 2015.

21. Tsai YH, VanDussen KL, Sawey ET, Wade AW, Kasper C, Rakshit S, Bhatt RG, Stoeck A, Maillard I, Crawford HC, et al: ADAM10 regulates Notch function in intestinal stem cells of mice. Gastroenterology 147: 822-834.e13, 2014.

22. Tanei T, Morimoto K, Shimazu K, Kim SJ, Tanji Y, Taguchi T, Tamaki Y and Noguchi S: Association of breast cancer stem cells identified by aldehyde dehydrogenase 1 expression with resistance to sequential Paclitaxel and epirubicin-based chemotherapy for breast cancers. Clin Cancer Res 15: 4234-4241, 2009.

23. Begg A, Stewart F and Vens C: Strategies to improve radiotherapy with targeted drugs. Nat Rev Cancer 11: 239-253, 2011.

24. Resetkova E, Reis-Filho JS, Jain RK, Mehta R, Thorat MA, Nakshatri $\mathrm{H}$ and Badve $\mathrm{S}$ Prognostic impact of ALDH1 in breast cancer: A story of stem cells and tumor microenvironment. Breast Cancer Res Treat 123: 97-108, 2010.

25. Ginestier C, Hur MH, Charafe-Jauffret E, Monville F, Dutcher J, Brown M, Jacquemier J, Viens P, Kleer CG, Liu S, et al: ALDH1 is a marker of normal and malignant human mammary stem cells and a predictor of poor clinical outcome. Cell Stem Cell 1: 555-567, 2007.

26. Morimoto K, Kim SJ, Tanei T, Shimazu K, Tanji Y, Taguchi T, Tamaki Y, Terada N and Noguchi S: Stem cell marker aldehyde dehydrogenase 1-positive breast cancers are characterized by negative estrogen receptor, positive human epidermal growth factor receptor type 2, and high Ki67 expression. Cancer Sci 100: 1062-1068, 2009.

27. Charafe-Jauffret E, Ginestier C, Iovino F, Tarpin C, Diebel M, Esterni B, Houvenaeghel G, Extra JM, Bertucci F, Jacquemier J, et al: Aldehyde dehydrogenase 1-positive cancer stem cells mediate metastasis and poor clinical outcome in inflammatory breast cancer. Clin Cancer Res 16: 45-55, 2010.

28. Blood $\mathrm{CH}$ and Zetter BR: Tumor interactions with the vasculature: Angiogenesis and tumor metastasis. Biochim Biophys Acta 1032: 89-118, 1990. 
29. Herren B, Levkau B, Raines EW and Ross R: Cleavage of beta-catenin and plakoglobin and shedding of VE-cadherin during endothelial apoptosis: Evidence for a role for caspases and metalloproteinases. Mol Biol Cell 9: 1589-1601, 1998.

30. Chang HY, Nuyten DS, Sneddon JB, Hastie T, Tibshirani R, Sørlie T, Dai H, He YD, van't Veer LJ, Bartelink H, et al: Robustness, scalability, and integration of a wound response gene expression signature in predicting breast cancer survival. Proc Natl Acad Sci USA 102: 3738-3743, 2005.

31. Mani SA, Guo W, Liao MJ, Eaton EN, Ayyanan A, Zhou AY, Brooks M, Reinhard F, Zhang CC, Shipitsin M, et al: The epithelial mesenchymal transition generates cells with properties of stem cells. Cell 133: 704-715, 2008.
32. Morel AP, Lievre M, Thomas C, Hinkal G, Ansieau S and Puisieux A: Generation of breast cancer stem cells through epithelial-mesenchymal transition. PLoS One 3: e2888, 2008.

33. Hennessy BT, Gonzalez-Angulo AM, Stemke-Hale K, Gilcrease MZ, Krishnamurthy S, Lee JS, Fridlyand J, Sahin A, Agarwal R, Joy C, et al: Characterization of a naturally occurring breast cancer subset enriched in epithelial-to-mesenchymal transition and stem cell characteristics. Cancer Res 69: 4116-4124, 2009.

34. Aktas B, Tewes M, Fehm T, Hauch S, Kimmig R and Kasimir-Bauer S: Stem cell and epithelial-mesenchymal transition markers are frequently overexpressed in circulating tumor cells of metastatic breast cancer patients. Breast Cancer Res 11: R46, 2009. 